\title{
My Body: Is It Me?
}

\author{
Thomas W. Smythe \\ Department of English, North Carolina Central University, Durham, USA \\ Email: thomaswsmythe@yahoo.com
}

Received October 28 ${ }^{\text {th }}$, 2011; revised December 10 $0^{\text {th }}$, 2011; accepted December $20^{\text {th }}, 2011$

\begin{abstract}
In this paper I will take the term "my" in the phrase "my body" to be typically used to refer to the self or person whose body it is. This raises a problem for materialism over how a body can own or have itself. I will articulate some ways in which we are and are not related to our bodies, and try to undo the linquistic knot of a body owning itself.
\end{abstract}

Keywords: Mind; Body; Ownership

\section{Introduction}

When we use the phrase "my body" the "my" can seem to refer to something distinct from the body; something that has a body. This can purportedly raise a problem for materialism. This is because it seems that "my" refers to what possesses the body; and does not seem to be identical with the brain or body. By materialism I mean the view that a human being is just a brain and a body, and that psychological characteristics are realized or instantiated in the brain.

I will begin by making a couple of preliminary points about the phrase "my body". The phrase "my body" is such that the "my" does not obviously refer to anything. It is not obviously a referring expression, or an expression that is used to refer to what has a body. Now either the "my" in "my body" is a separate referring expression or it is not such a referring expression. Suppose that it is not used to refer to anything. If that is the case, then I think that its role in the language can be construed as being like a demonstrative. It is like the case in which I point blindly in front of me and say "I wonder what that is". In this case I may have no substantive idea of what I am pointing to other than something or other in front of me occupying space. "My" functions something like "that" in such a case. My body's being "mine” has no cognitive substance (Levine, 2003).

However, I shall not take this line of thought. I am assuming that the "my" of "my body" is a first-person pronominal adjective that is used as a referring term. It refers to me (whatever I am). "My" picks out a subject in a referential way. It is used to refer to the self or person that has a body. Anyone who does not agree with this assumption, will not agree with the rest of the paper. Second, I am directing my attention to the phrase "my body", and not to the much discussed phrase "I have a body". I am not discussing whether the "I" in "I have a body" is a referring expression, since I have nothing to add to the extant literature on that topic (Anscombe, 1974; Malcolm, 1995). Now for a statement of the problem.

\section{Discussion}

It seems that I cannot consider my brain to be the subject of experience and perception because it seems that I am a detached observer from my brain and body. The brain is something that I possess, and so it does not seem that we can capture the subject of experience by identifying it with anything physical like the brain. This argument can also be applied to dualism, or to any philosophical view that the subject of consciousness is a mental substance, a pure ego, or an immaterial substance. I can speak of my mind, and take it as another object to be talked about and scrutinized in relation to a subject. One might conclude that this type of argument will, therefore, provide us with equally strong (or weak) reason to reject any view that construes the subject of psychological states as a substance where the psychological states are attributes of the substance.

I think that what we should say is that this line of argument, even if it is an intelligible objection at all to picking out something as being the subject of psychological states, will result in the absurd consequence that there is no subject of experiences, that there is nothing which thinks, wills, perceives, has ideas, has a body and has a mind. This is exactly what the materialist Daniel Dennett has concluded in a recent article. Dennett says that when we think about a self as a single source of experience we

... try to posit a unified agent... what I call the center of narrative gravity. This is yet another abstraction, not a thing in the brain, but still a remarkably robust and almost tangible attractor of properties... Who owns your car? You do. Who owns your clothes? You do. Who owns your body? You do! When you say "This is my body", you certainly aren't taken as saying “This body owns itself” (Dennett, 1989: p. 104).

For Dennett, what is at issue in such ways of speaking is whether possessive pronouns such as "my" and "mine" always indicate ownership or possession of something by something else (an owner or possessor). If to say this is "my body" means that a particular human body is related to me the way my car is related to me (as something distinct from me which I own), the surely one will be stopped short by the view that I am my brain and body, for owners do not own themselves. If I am that which possesses or owns my brain and body, then surely I cannot be my brain and body. For whatever I am I cannot own or possess that.

Elsewhere Dennett expresses the same worry. He says

Who owns your car? You do. Who owns your clothes? You do. Then who owns your body? You do! When we say this is my body, you certainly are not taken as saying, this body owns itself. 
But what can you be saying then? If what you say is neither a bizarre and pointless tautology (this body is its own owner, or something like that) nor the claim that you are an immaterial soul or ghost puppeteer who owns and operates this body the way you own and operate your car, what else could you mean? (Dennett, 1991: p. 418).

I shall argue that the relation between me and my body can be specified in several ways, most of which do not refute materialism. Some of them are ontologically neutral in the sense that they do not imply either that some form of dualism is true, or that some form of materialism is true. Therefore, they do not present a difficulty or threat to materialism. I will also present some ways that I seem to be related to my body that are not genuine.

But first I will briefly discuss Dennett's solution to this puzzle. Dennett, if I am interpreting him correctly, says that I do not own my body because there is nothing to own the body. The "self" is an abstraction or fiction (Dennett, 1991: pp. 420, 428). It is like the equator or lines of latitude or longitude. It is not a concrete existing thing that has a body. However, I think that his view has some shortcomings. I will briefly state why I think that this is a mistake.

First, in common sense we think of the self (myself) as being a causal agent that is responsible for its actions. An abstraction cannot fill that role. Second, we think of the self as a mental thing that has mental states. Third, we think of the self as unified both synchronically and diachronically. Fourth, we ordinarily think of the self as being a subject of experience, and as occupying a point of view. None of these deeper-lying aspects of the self can be happily construed as an abstraction (Strawson, 1997).

I only wanted to mention these difficulties with Dennett's positive view of the self to indicate that this is not the path I think a materialist should take on the supposed owner of one's body. Before I return to the main topic of the paper, I need to make some further clarifications.

In this paper I talk a lot about the self. This is not a paper about the metaphysics of the self. By "self” I just mean "person" although the exact nature of each is the subject of some controversy. My main concern is with the implications of the way I am related to my body for the mind-body problem. I talk about the self when discussing substance dualism, because for the dualist the self or person is a mind or soul that is capable of existing in a disembodied state. For the materialist, the self or person is just a material thing. I also bring in points about personal identity in order to trash one of the putative ways that I seem to be related to my body. This paper is not about personal identity, however. I am concerned to defend materialism vis-àvis possible dualistic conclusions that can be drawn from considerations about my relation to my body. I now turn to some ways in which we seem to be related to our bodies, but are not so related when examined critically.

One way it might be thought that I can be related to my body can be stated in terms of exclusivity and uniqueness. There is a sense in which this body that I trundle around in is exclusively and uniquely mine. It is my body and no one else's. Ed Fink has suggested to me that this may seem to be a legitimate way that I am related to my body. But the notion that this body is uniquely and exclusively mine needs further explanation. First, William P. Alston has told me that I need to distinguish between necessary and contingent exclusivity. I will discuss the former. What does it mean to say my body is exclusively mine?
One thing it can mean is that no one else can share my body with me. No one else can have my body. I cannot think of anything else that can be meant by saying my body is uniquely and exclusively mine.

If this is what it means to say I am related to my body, it is clear from the philosophical literature on personal identity that I am not related to my body in this way. Dualists are fond of imagining cases where people change bodies by having their soul move to another body. Materialists do not think that such an exchange of bodies is possible as a matter of fact, although it may be logically possible. Some materialists even deny that such an exchange of bodies is even logically possible or intelligible.

Materialists and dualists both think that brain transplants are logically possible where one acquires a completely new body while remaining the same person. In fission cases, where two brain hemispheres are allotted to different persons, two people seem to occupy one body. Then there are cases of multiple personality disorders where several selves are manifested in one body. As a result, there does not seem to be a case of ownership where this body of mine is unshareable with anyone else. I conclude that this alleged way of being related to my body is bogus. We will have to look elsewhere to find a way in which I am genuinely related to my body.

A second way we are not related to our bodies is one in which I can be said to be related to my mental states as their subject. As a subject of experience I possess or own my thoughts and sensations. This is my pain and it is had by me. Similarly, I can be said to have a body.

Owning my mental states as their subject does not make me the owner of my body. So there is no relation in that sense. But there might be an analogy between my owning my mental states and my owning my body. The difficulty is one of specifying what "own" means in this comparison. In what sense, if any, do I "own” my mental states? This has to be specified, and I do not see how to do it.

A third way that I seem to be related to my body but am not comes from the fact that my body has a causal relation to the subject of my mental states. In other words, my body is a causal factor, it causes my mental states and my being the subject of those mental states.

According to William Alston in correspondence this way of being related to my body is bogus. Light waves in my environment are causal factors for my consciously seeing things. Yet I don't have them in any way. The same goes for the objects I see. They cause my seeing them, but I don't have them. I now turn to ways that we are genuinely related to our bodies.

The first way in which I am related to my body is that my brain and body are related to me, as subject, as parts to a whole, as when we say that the chair possesses a seat and legs. Here one might think that if my having a body involves a part-whole relationship, yet it does not follow that I am something different from my brain and body, any more than it follows from the fact that a chair has a seat and frame that the chair is something different from the sum of its parts.

However, this would be too facile. We can say things about a chair, such that it is a portable seat for one, which we cannot say about the legs or other parts. The chair has a function as a whole that is not shared by the sum of its parts. Similarly, it is because people acknowledge real wholes that they come the think of an "I" that is separate from one's body and mental states. I will argue that this does not impugn materialism, which 
I am concerned to help out of these difficulties.

The self could be a real whole without being nonphysical or immaterial. Functionalism accounts for the mind in functional terms that are compatible with counting the self as more than the sum of one's bodily parts. The mind is realized in material phenomena in spite of the fact that you can say things about the whole person and his mental states that you cannot say about his bodily parts. So this relation to my body does not raise a problem for materialism. I think that most all of the versions of functionalism in the literature will allow for the minimal claim that mental states can be realized in the brain. Thus I can avoid saying what version of functionalism I have in mind.

One can object here that I cannot be related to my whole body in the relation of having a body, and at the same time be my body. That would be the body having itself. Similarly, I cannot say the self is the brain and that I have a brain, for William P. Alston pointed out to me that this would be tantamount to saying the brain has itself. What can a materialist say in reply to this point? This objection is central to the difficulties I have raised about my relation to my body. For a person's having a body would be impossible on a materialist view. I will wait until the end of the paper to deal with this difficulty.

A second way that I am related to my body besides the above is the legal sense of ownership, as in owning a piece of property. A person can be said to be related to her body in a legal sense. Suppose a woman claims "My body!" in a rights-asserting sense. What, if anything, does this imply about the ownership of the body? She can be said to have control over her body in both a moral and legal sense. She has a legal control of her body. However, this may not convince us that she "owns" her body in a legal sense. Other cases can be cited that make legal ownership of the body more plausible. A prostitute can be said to sell her body as though it were a piece of property. Others can be said to use her body as an object or a piece of property. There is the further case of buying and selling organs of the body to people who need heart, liver, or kidney transplants. Here the donor can be said to have a legal ownership of his or her body whose parts they are selling. Finally, there is the possibility of brain transplants. A person with a diseased brain may donate their body to someone who needs a new body for their intact brain. In this example the donor can clearly be said to own his or her body that they are donating to the person with the healthy brain. So there are examples where bodily ownership in a legal sense is perfectly natural ways of speaking.

It is important for the defense of materialism to point out that this legal sense of owning my body does not impact on the controversy between dualism and materialism. I can own my body legally and be essentially an immaterial mind, or own my body legally and yet I may be nothing more than my brain and body. So the materialist has nothing to fear from the legal sense of bodily ownership. We turn now to another sense in which I may be said to own or possess my body.

The final sense in which something is my body is probably the most obvious and important. What makes this body my body is that it is the one that I perceive things through and act through. I act through this body when certain parts of my body are subject to my will. I can move certain parts of my body at will. I cannot move any part of a body that is not mine just by an act of will. Of course, someone could be paralyzed and not be able to move their body at will. I perceive the physical environment through my body. It can be pointed out that I perceive my own body differently than I perceive other bodies. When I feel my tummy ache, I can locate the feeling in my tummy, but when I feel your tummy I do not locate that feeling in your tummy. Is this way of being related to my body obviously incompatible with materialism in any way?

Perception of the physical environment is an old bugbear for materialists. There is no space in this paper for such a discussion. Suffice to say that materialists are not without their resources. As for the will, this is also somewhat controversial. Materialists have given accounts of the will. A rehashing of such accounts of perception and the will here would not add anything of significance to the primary topic of the paper. Besides an adequate treatment of these concepts would require another paper. The main point is that this relation between me and my body is not an obviously fatal defect in materialism.

Someone may argue that there is a difference between the locutions "myself" and "my body". "Myself" refers to the one who is identical with I, but the "my" in "my body" refers to a distinct self or soul that is separate from the body. One could talk that way if one were a dualist. However, this is not an argument for dualism. I am considering what one would say if they were already committed to some form of materialism.

\section{Conclusion}

This completes my canvass of the ways in which I am not related to my body, but only seem to be, and the ways I am genuinely related to my body. We have found that only one of them raises a problem for materialism. The difficulty arose in the part-whole relation I have to my body. A materialist cannot say that I have a whole body and at the same time say that I am my body. For, as pointed out before, that would be tantamount to saying that the body has itself. The materialist will have to say that I don't have a body. I am my brain and body.

William Alston in correspondence has suggested a possible way around this difficulty for the materialist. What we need is some way to escape the inescapable thesis that one cannot own one's self, that there has to be a distinction between owner and owned. Alston's suggestion is to treat identity as a limiting case of ownership where the owner-owned relationship is at the limit of a continuum of increasingly more intimate relations between owner and owned. Moving freely between differences between owning and having, the continuum of thing had might range from pencil to automobile to headache. Many more items could be inserted. But on the assumption that I am even more intimately related to myself than to my headache, then my relation to myself (viz., identity) is the limit of a series of earlier members that do not give rise to the same objection. This might make it at least coherent or intelligible to think of my having myself.

I will adopt Alston's suggestion as possible way of me owning myself or my having myself. It may well be that, in the end, the materialist will have no way of making sense of this. But it was worth a try.

\section{REFERENCES}

Anscombe, E. (1974). The first-person. In S. Guttenplan, (Ed.), Mind and language: Wolfson college lectures (pp. 45-65), Oxford: Oxford University Press.

Dennett, D. C. (1991). Consciousness explained. New York, NY: Little, Brown, and Company.

Dennett, D. C. (1989) The origin of selves. Cogito, 3, 163-173.

Levine, J. (2001). Purple haze: The puzzle of consciousness. Oxford: 


\section{T. W. SMYTHE}

Oxford University Press. doi:10.1093/0195132351.001.0001

Malcolm, N. (1995). Whether "I" is a referring expression. In Wittgensteinian themes (pp. 16-26). Ithaca: Cornell University Press.
Strawson, G. (1997). The self. Journal of Consciousness Studies, 4, 385-388. 